\title{
Comparative Analysis of English Prepositions and Armenian Case Endings
}

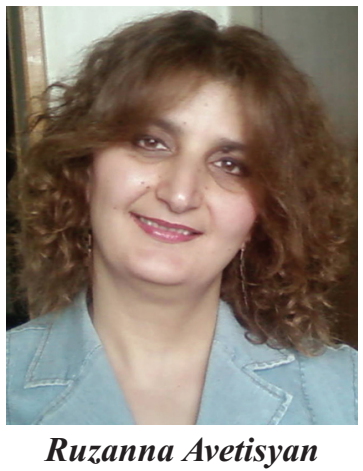

According to the morphological and typological classification of the languages at issue, as well as relying on the common structural features, the English language is classified in the series of analytic languages. In English such means as word order, stress, intonation, modal words are used mainly as means of expressing grammatical meanings. Whereas the Armenian language belongs to the series of synthetic languages. Inflectional morphology makes it possible to clarify the grammatical meanings expressed in the Armenian language.

The case system is quite developed in Armenian. In the latest works of grammar the synthetic notion and the definition of languages is being criticized on the basis of the fact that the case meaning can't be considered to be similar with the concrete relation and the synthetic function expressed by the case. Each case has got its basic meanings and synthetic functions on which the morphological meaning of the case is based. In the Armenian language it's only the Common (Nominative) Case that opposes to all the other cases in its form: it hasn't got any typical ending and it is considered to be the basic form for the other so-called inflectional cases.

Modern English doesn't have a rich case system. Here the synthetic applications typical of the case meaning are not expressed by means of case endings (inflections) but with the help of modal words (Blokh 1983:65). So prepositions here play the role of the modal words. It is just with the help of prepositions that different grammatical meanings of one and the same word are expressed.

For example:

$$
\begin{aligned}
& \text { hnnnghg - from the street } \\
& \text { hnnngnuv - in the street } \\
& \text { thnnngh - of the street, etc. }
\end{aligned}
$$

If case endings are considered to be morphemes, then prepositions are part of the vocabuary of the language as independent words. Many prepositions, mainly the prepositions of 
place are considered to be words with full meanings and they can function as independent members of the sentence. Whereas the case endings lack any lexical meaning of their own. Yet the role of prepositions and case endings in some languages are equal.

Prepositions are wildly used linguistic units in Modern English. Used with the noun or the noun substitute, i.e. with the Pronoun and the Gerund, they express the relation between that same word and another word in the sentence. Other parts of speech which are used as nouns can take prepositions as well (Leech, Svartvik 1983:255).

Combinations of a notional word with a functional word are equivalent to separate words by their nominative function. Since a functional word expresses some abstract relation. Such combinations, as a rule, are quite obviously non-self-dependent: they are artificially isolated from the context.

In terms of their morphological structure prepositions in Modern English are simple (on, in, at, for, with, etc.), derivative (behind, below, across, along, etc.) and composite (in front of, by means of, as for, etc.). They may have a meaning of their own.

For example:

Her sister appeared carrying a wine-glass in which there was a raw egg, with a little cherry on it.

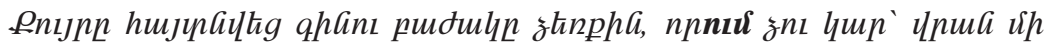
unpn pul:

The path felt springy beneath his feet.

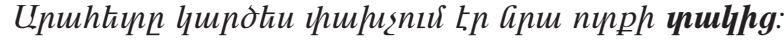

He dropped into a chair beside his mother.

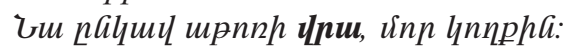

Expanding the cited formative phrases with the corresponding notional words one can obtain notional phrases of contextually self-dependent value. There are prepositions which express concrete meanings: that of place (on, in, at, out of, etc.), position (above, by, over, in front of, under, beneath, behind, below, on top of, etc.), motion (towards, into, though, along, away from, etc.), direction (up, down, along, across, etc.) and time (after, before, during, for, in, on, at, etc.). There are prepositions expressing different abstract relations (by, with, for, against, because of, instead of, owing to, according to, etc). Some prepositions may have a double meaning (Leech, Svartvik 1983:93).

For example:

I've been here for already two weeks.

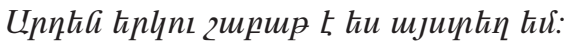

He has brought a letter for you.

um phq huufun auviul 5 phink:

I was punished for my little joke.

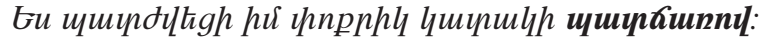

They went for a walk.

unuap qunumaph qaimgha: 
They sent for a doctor.

unuap nınunligha pollh hkinlihg:

As for syntagmatic groupings of functional words, they are essentially analogous to separate functional words and are used as connectors and specifiers of notional elements of various status. Functional phrases of such and like character constitute limited groups supplementing the corresponding subsets of regular one-item functional words, as different from notional phrases which, as free combinations, form essentially open subsets of various semantic destinations.

For example:

No one could account for his objection to our plan.

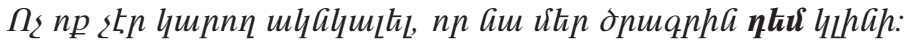

He should be ashamed of himself.

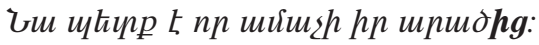

You shouldn't rely on him.

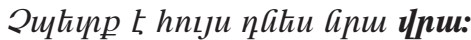

Who is going to look after your children while you are away?

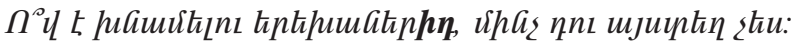

I've been dependent on both of you so long.

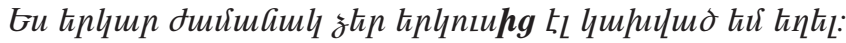

The use of prepositions is determined by different factors. Sometimes it may be quite free depending on the meaning that is meant by the speaker. In many cases the choice of the preposition is determined by the main word with which it is used. In other cases the choice of the preposition depends on the noun that follows it:

For example:

Who was the first to speak at the meeting?

$\Lambda^{\circ} y$ ukinp 5 unughan hnukn dnnnyha:

He went there on business.

um qnnony qaug uјaintin:

He is now on a concert tour in Europe.

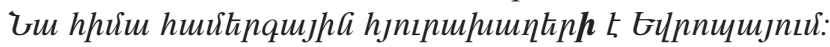

I'm planning to finish it in February.

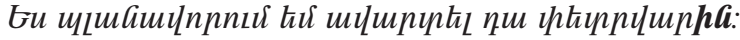

Prepositions, like all the other functional words re-interpreted by syntactic approach, also reveal some important traits that remained undiscovered in earlier descriptions. Functional words, considered by their role in the structure of the sentence, are proved to be exposers of various syntactic categories, i.e. they render structural meanings referring to phrases and sentences in constructional forms similar to derivational (word-building) and relational (grammatical) morphemes in the composition of separate words. 
The corresponding meanings of the English prepositions have their equivalent forms in Armenian. Those meanings are expressed by the case category in Armenian. Case is the immanent morphological category of the noun manifested in the forms of noun declension and showing the relations of the nounal referent to other objects and phenomena. Thus, the case form of the noun, or contractedly its "case" (in the narrow sense of the word), is a morphological-declensional form.

In modern English there are many prepositions denoting time relationships or duration. The equivalent meanings in Armenian are expressed by the Dative case:

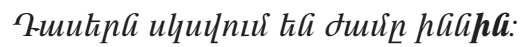

Classes begin at 9 o'clock.

bnluman qhinghl 5 likuqhinha:

Yerevan is beautiful at midnight.

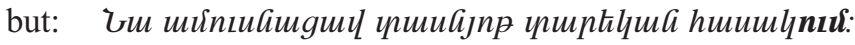

She got married at the age of 17.

As is evident from the above examples the Armenian case ending - $h a / n u d$ corresponds to the preposition of time at in English. The English preposition from has got the equivalent meaning of the Armenian case endings - $h g / n\llcorner g$. The corresponding meaning of the preposition by is expressed by the case endings $-n \eta / J u v\{$ in the examples below:

Most people work from 9 to 5 .

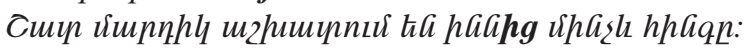

They flew from Paris to Rome.

unuap Фunhqhg pnua <nnu:

I translated the article from Russian into English.

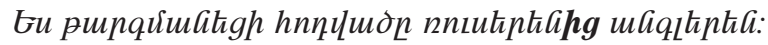

He likes to travel by car.

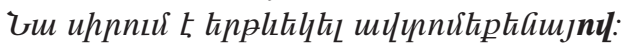

Generally in both languages prepositions are considered to be functional parts of speech. These are words that play the role of interpositional elements, determining the relations of notional words to one another.

Thus, according to the comparison of the case meanings in Armenian and the corresponding meanings of prepositions in English, it can be mentioned that there is a certain kind of correspondence between them which can bring to the creation of several useful grammar rules which may be observed by translators. It will naturally make things easier for them while doing translations from Armenian into English or vice versa. 


\section{References:}

1. Gordon, E.M., Krylova, I.P. (1980) A Grammar of Present-Day English. M.: Vyshaya Shkola.

2. Murphy, R. (1967) English Grammar in Use. Cambridge: Cambridge University Press.

3. Thomson, H., Martinet, E. (1986) A Practical English Grammar. New York: Oxford University Press.

4. Vince, M. (2008) Intermediate Language Practice. English Grammar and Vocabulary. China: Macmillan.

5. Leech, G., Svartvik, J. (1983) A Communicative Grammar of English. M.: Prosveshcheniye.

6. Blokh, M.Y. (1983) A Course in Theoretical English Grammar. M.: Vyshaya Shkola.

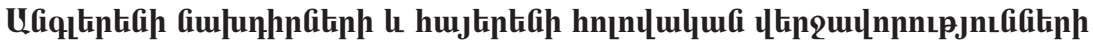

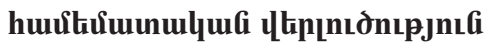

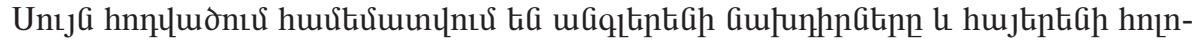

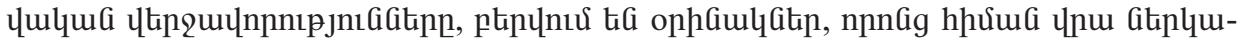
juglnư

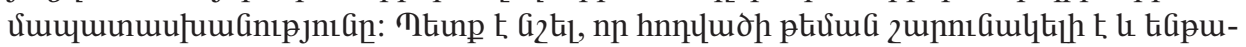

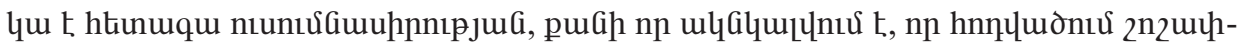

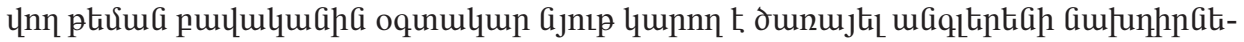

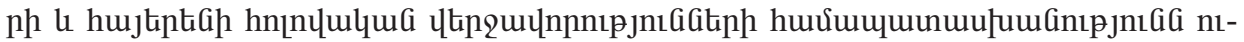

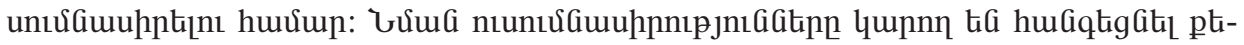

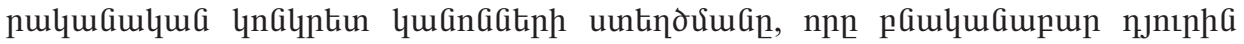

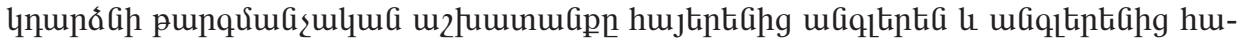
jtintig: 